\title{
S sciendo MONITORING THE QUALITY OF LASER CUTTING
}

doi:10.2478/mape-2018-0018

Date of submission of the article to the Editor: 03/2018

Date of acceptance of the article by the Editor: 05/2018

Ing. Rastislav Bernát, PhD.

Ing. Zoltán Záležák, PhD.

Doc. Ing. Jozef Žarnovský, PhD.

Mgr. Norbert Kecskés, PhD.

Ing. Milan Peniaško

Slovak University of Agriculture Nitra, Slovac Republic

Dr inż. Katarzyna Midor

Silesian University of Technology, Poland
MAPE 2018, volume 1, issue 1, pp. 137-145

\begin{abstract}
In engineering industry the production of components begins with separation of the base material and this technological operation can be time consuming, especially in large-scale production. Such production can be made more efficient by means of laser technology focusing on material cutting. Efficiency of cutting is determined not only by shortening of working time or energy saving, but also by the required cutting quality. In the paper we compare the impact of cutting speed changing and laser beam performance on the cutting edge quality. Based on requirements of dimensional accuracy and preset roughness of the cutting edge, we evaluated the cutting quality of laser in samples of different materials. Measured values of sample dimensions and roughness are compared in conclusions of the paper, where we estimate whether the samples meet specified requirements of dimensional accuracy and roughness of the cutting edge in order to make the production process more efficient.
\end{abstract}

Keywords: quality, separation of material, laser cutting, roughness, efficiency

\section{INTRODUCTION}

In engineering industry demanding requirements for precise and rapid production of components, production efficiency and environmental friendliness of the entire production process are being introduced. As a result of these requirements, progressive methods have been included in the production process which greatly utilize the physical principles of machining. One of the most up-to-date machining method is laser beam cutting which is the subject of our research work. Laser cutting is a process which enables to constantly adapt the resulting product to production or customer requirements (Benko et al., 2000, Kovac et al., 2005). By means of the laser device, it is possible to modify the cutting parameters to meet the required standards. The result of our research is the introduction of large-scale production of dimensionally identical samples from different materials with defined requirements on the accuracy of the cutting edge dimension and its roughness (Bernat, 2008; Gajtanska et al., 2004, Jimenez et al., 2017). Based on dimensional accuracy and roughness requirements of the cutting edge determined by the manufacturing organization, we evaluate the cutting quality graphically by comparison of measured values at changing fiber laser cutting parameters. The materials at which we monitor this impact are used for construction purposes in the field of engineering and are cut into component parts according to customer's requirements (Balla et al., 2006). 
According to research results, we can determine the appropriate adjustment of the cutting parameters and thus to improve the efficiency of the production process, either by increasing the cutting speed or by reducing the laser beam power.

\section{METHODOLOGY OF RESEARCH}

\section{Characteristics of the used laser equipment}

The MSL 3001. 15L Laser Cutting Device works on the IPG Fiber Laser System principle and is shipped to the cutting head by optical fiber (Fig. 1, Table 1).

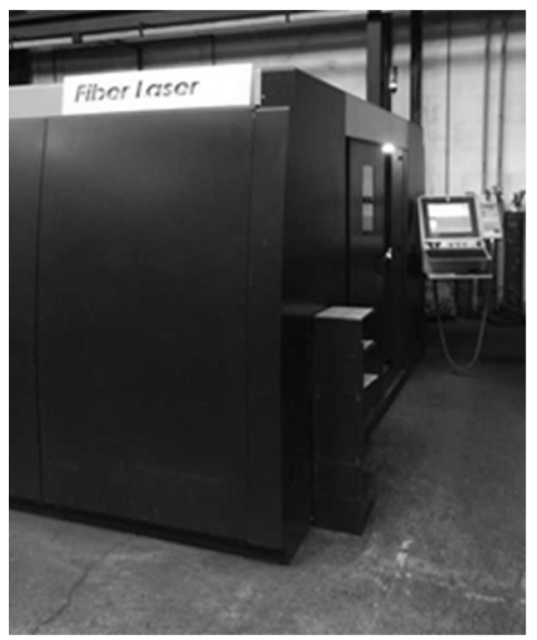

Fig. 1. Laser cutting device MSF

Table 1

Technical characteristics of the cutting device MSF $3001.15 \mathrm{~L}$

\begin{tabular}{|l|l|}
\hline Type & MSF $3001.15 \mathrm{~L}$ \\
\hline Serial number & $1486 / 12$ \\
\hline Year of production & 2015 \\
\hline Weight & $650 \mathrm{~kg}$ \\
\hline Operating length & $3000 \mathrm{~mm}$ \\
\hline Operating width & $1500 \mathrm{~mm}$ \\
\hline Number of cutting heads & 1 \\
\hline Positioning speed & up to $130 \mathrm{~m}^{\mathrm{min}} \mathrm{min}^{-1}$ \\
\hline Maximum cutting speed & max. $30 \mathrm{~m} \cdot \mathrm{min}^{-1}$ \\
\hline Positioning accuracy & $\pm 0,03 \mathrm{~mm}$ \\
\hline Power supply & $3 \mathrm{~L}+\mathrm{N}+\mathrm{PE} \mathrm{AC} 400 / 230 \mathrm{~V}, 50 \mathrm{~Hz}$ \\
\hline
\end{tabular}

The principle of the laser device is a portal on which a laser cutting head is placed by means of which the material can be cut. The device includes a control panel, a hydraulic exchange table with a grate, a hydraulic aggregate and a built-in conveyor for waste disposal and suction (Geleta, 2013, Micietova, 2001).

This device uses IPG laser as a source of laser radiation. This source consists of active optical fibers and semiconductor diodes that produce light radiation for exciting active optical fibers inside the source. The generated laser radiation is transported to the laser cutting head by means of a protected and flexible fiber in the energy carrier. The HIGHYAG cutting head is used in the device and the optical fiber is led through the energy carrier (Simon et al., 2017). The modular design allows its integration into dynamically moving laser beam cutting devices. For communication purposes of the staff with the control system of the device a control panel, which is reliable and easy to operate, is used. It allows to prepare and edit cutting plans simultaneously with the cutting process and to change the cutting parameters of the device (Simon et al., 20170). The software uses predefined parameters that depend on the type of material and its thickness. 


\section{Characteristics of cut samples}

Two types of material were used to monitor the quality of the fiber laser cut.

- non-alloy structural steel 11373 ,

- stainless steel 17240.

The sample sizes are shown in Table 2 and technical figure in Figure 2. We estimated the tolerance values of the width dimension and the required value of the mean arithmetic deviation of the profile $\mathrm{Ra}, \mu \mathrm{m}$.

Table 2

Used materials

\begin{tabular}{|c|c|c|}
\hline Material designation & $\begin{array}{c}\text { Dimensions: } \mathbf{~} \mathbf{x} \mathbf{~ w ~} \mathbf{x h} \\
{[\mathbf{m m}]}\end{array}$ & $\begin{array}{c}\text { Required roughness, } \\
{[\boldsymbol{\mu m}]}\end{array}$ \\
\hline steel 11373 & $40 \times 20 \times 6$ & $\mathrm{Ra} \mathrm{1.6}$ \\
\hline steel 17240 & $40 \times 20 \times 6$ & $\mathrm{Ra} \mathrm{3.2}$ \\
\hline
\end{tabular}
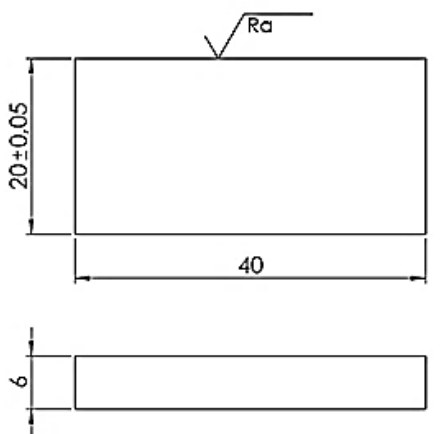

Fig. 2. Monitored material samples dimensions

The sample sizes are defined by the technical documentation with requirements on dimensional accuracy and roughness of the cut edge $\mathrm{Ra}$ in $\mu \mathrm{m}$.

We define the following:

- controlled nominal width $w$ with a tolerance of $\pm 0.05 \mathrm{~mm}$, based on which the cutting accuracy is determined.

- roughness of the cutting edge for steel 11373: Ra $1.6 \mu \mathrm{m}$ and for stainless steel 17240: Ra $3.2 \mu \mathrm{m}$.

\section{Digital micrometer Mitutoyo}

In order to measure the accuracy of dimensions of cut samples by the laser device, we used a Mitutoyo digital micrometer (Table 3).

The micrometer is used to measure external dimensions. The measured value is shown on a display.

Table 3

Technical characteristics of digital micrometer

\begin{tabular}{|l|l|}
\hline Range & $0-25 \mathrm{~mm}$ \\
\hline Resolution & $0.001 \mathrm{~mm}$ \\
\hline Tolerance & $\pm 0.002 \mathrm{~mm}$ \\
\hline
\end{tabular}

We monitored the nominal width $w$ with the required tolerance of $\pm 0.05 \mathrm{~mm}$. We measured 5 times along the sample in areas indicated in Figure 3. 


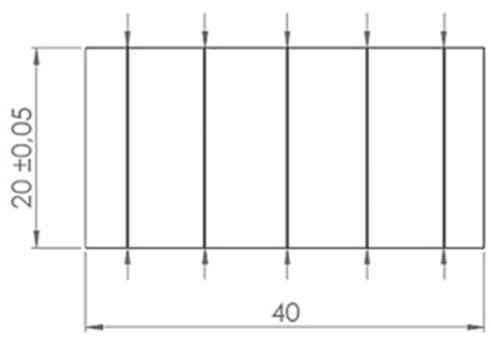

Fig. 3. Measuring areas

Micrometer measurement procedure:

Attach the micrometer to the stable holder Fig. 4 and then measure the samples whose dimensions are written into a pre-established protocol.

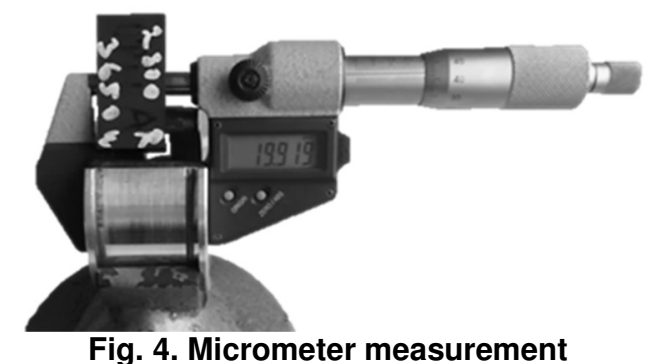

Digital roughness gauge Mitutoyo Surftest 301

In order to evaluate the surface roughness of the cut samples we used the digital roughness gauge Mitreoyo - SURFTEST - 301 (Fig. 5).

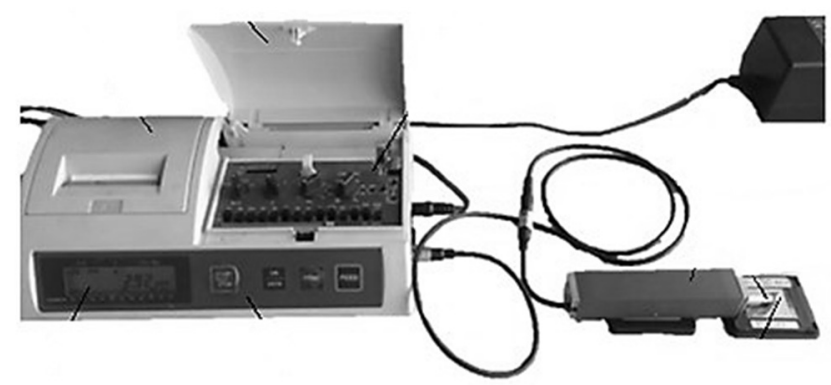

Fig. 5. Mitutoyo Surftest 301

The device uses a diamond tip to capture the surface and includes a power supply, a slider with a detector and tip, an attachment cable, setting switches, a control panel, a display screen and a printer.

Table 4

Technical characteristics of the roughness gauge

\begin{tabular}{|l|l|}
\hline Range for Ra & $0.01-100 \mu \mathrm{m}$ \\
\hline Resolution & $0.01 \mu \mathrm{m}$ \\
\hline Touch & diamond tip \\
\hline
\end{tabular}

Cutting edge roughness is to be measured in areas with the greatest surface roughness. Cutting of material with a thickness of $6 \mathrm{~mm}$ results in an uneven cut. The largest surface changes are visible in about $2 / 3$ of the sample thickness and in the area of a projecting beam of material. During the measurement it is important that the measuring tip moves perpendicularly to the direction of formed inequalities, i.e. perpendicular to the direction of laser beam. Measurement is carried out in five areas shown in Figure 6. 


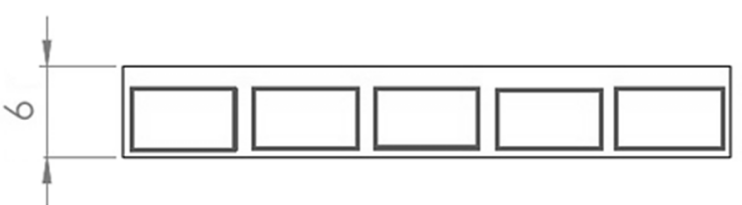

Fig. 6. Mitutoyo Surftest 301

\section{RESULTS}

Table 5

Dimensional accuracy values at changing cutting speed - material 11373

\begin{tabular}{|c|c|c|c|c|c|c|c|}
\hline \multirow{6}{*}{$\begin{array}{l}3 \\
0 \\
10 \\
0 \\
\text { ㅇ } \\
\text { 䒓 } \\
\text { 윽 } \\
0\end{array}$} & Sample & 1. & 2. & 3. & 4. & 5. & \multirow{6}{*}{$\begin{array}{l}E \\
E \\
\stackrel{N}{N} \\
\text { क }\end{array}$} \\
\hline & No. $1 v_{1}=2$ & 19.939 & 19.936 & 19.937 & 19.926 & 19.921 & \\
\hline & No. $2 \mathrm{v}_{2}=2.5 \quad \mathrm{~m} \cdot \mathrm{min}^{-1}$ & 19.919 & 19.953 & 19.886 & 19.909 & 19.924 & \\
\hline & No. $3 v_{3}=2.8 \mathrm{~m} \mathrm{~min}^{-1}$ & 19.981 & 19.987 & 19.992 & 19.986 & 19.983 & \\
\hline & No. $4 \mathrm{v}_{4}=3.2 \mathrm{~m} \cdot \mathrm{min}^{-1}$ & 20.024 & 20.020 & 20.039 & 20.027 & 20.021 & \\
\hline & No. $5 \mathrm{v}_{5}=3.25 \mathrm{~m} . \mathrm{min}^{-1}$ & 20.013 & 20.002 & 20.006 & 20.015 & 20.001 & \\
\hline
\end{tabular}

Figure 7 (a) shows the individual measurements of each sample, the upper tolerance limit (UTL), the lower tolerance (LTL) and the nominal size (NS) of the sample. Based on dimension tolerance values it is possible to evaluate if the size of the sample falls into the tolerance field or exceeds its value. We see that the worst cutting procedure is on samples 1 and 2 . Samples exceed the lower tolerance limit and therefore do not meet the specified requirements for dimension.

Dimensions of samples 3, 4 and 5 are in the tolerance field and satisfy the requirements of specified dimension.

The measured dimensions of stainless steel samples 17240 cut at cutting speed $(v)$ with a constant laser power $(P)=4000 \mathrm{~W}$ are listed in Table 6 and shown in Figure 7 (b) as a change of sample sizes at changing cutting speed.

a)

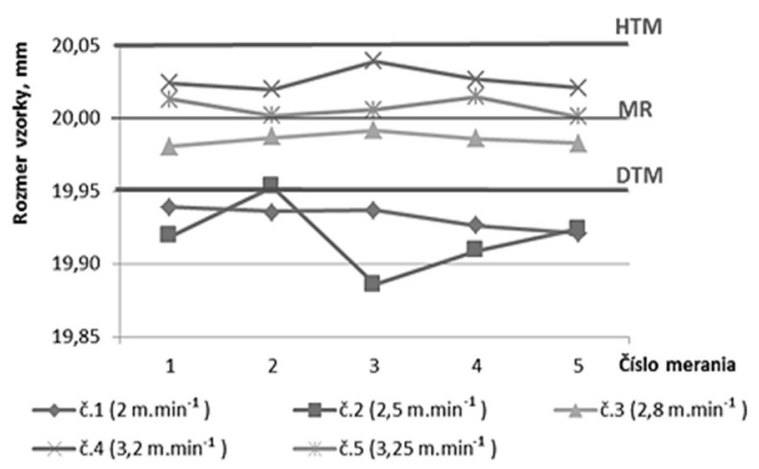

b)

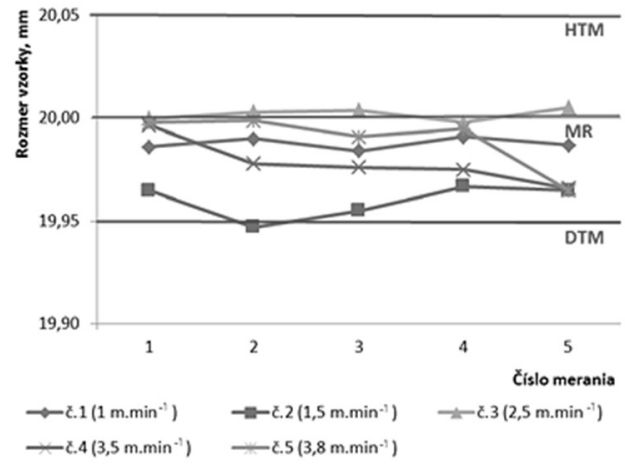

Fig. 7 Comparison of dimensional accuracy at changing cutting speed; (a) 11373, $P=3650 \mathrm{~W}$, (b) 17240, $\mathrm{P}=4000 \mathrm{~W}$

Table 6

Dimensional accuracy values at changing cutting speed - material 17240

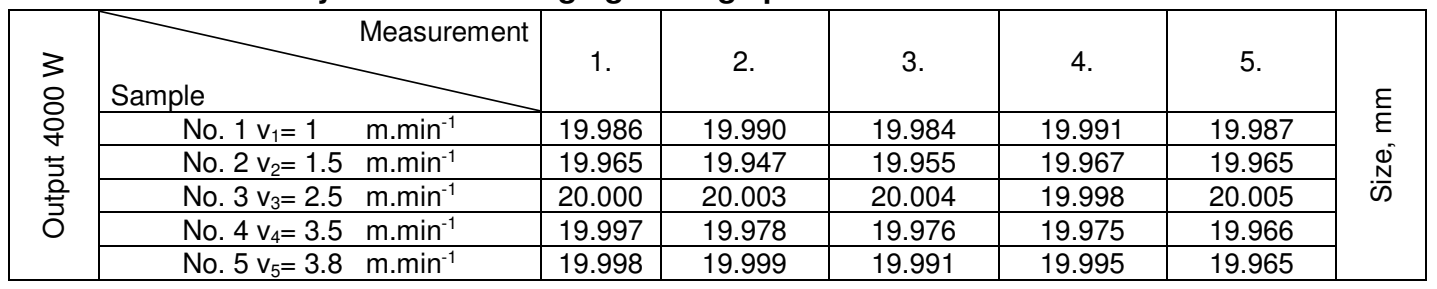


Table 7

Values of roughness at changing cutting speed - material 11373

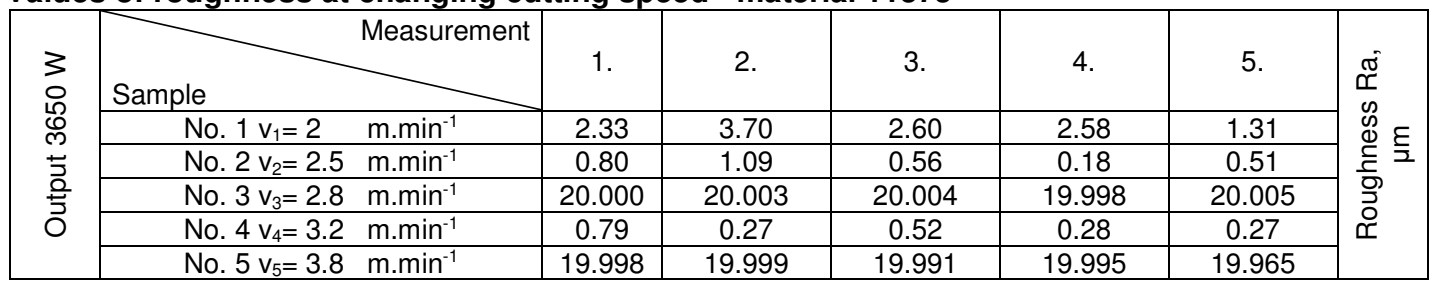

Table 8

Values of roughness at changing cutting speed - material 17240

\begin{tabular}{|c|c|c|c|c|c|c|c|c|}
\hline \multirow{6}{*}{ 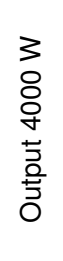 } & Sample & Measurement & 1. & 2. & 3. & 4. & 5. & \multirow{6}{*}{ 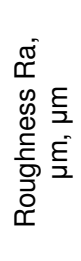 } \\
\hline & No. $1 v_{1}=1$ & $\mathrm{~m} \cdot \mathrm{min}^{-1}$ & 2.34 & 5.20 & 5,09 & 5.06 & 3.97 & \\
\hline & No. $2 \mathrm{v}_{2}=1.5$ & $m \cdot \min ^{-1}$ & 0.80 & 1.09 & 0.56 & 0.18 & 0.51 & \\
\hline & No. $3 v_{3}=2.5$ & $\mathrm{~m} \cdot \mathrm{min}^{-1}$ & 4.65 & 3.79 & 4,78 & 2.70 & 2.45 & \\
\hline & No. $4 v_{4}=3.5$ & $\mathrm{~m} \cdot \mathrm{min}^{-1}$ & 0.79 & 0.27 & 0.52 & 0.28 & 0.27 & \\
\hline & No. $5 v_{5}=3.8$ & $m \cdot m^{-1}$ & 2.47 & 1.83 & 3,89 & 2.55 & 2.65 & \\
\hline
\end{tabular}

a)

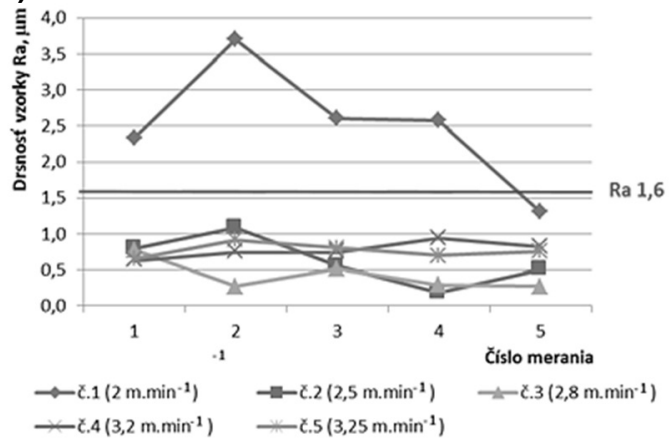

b)

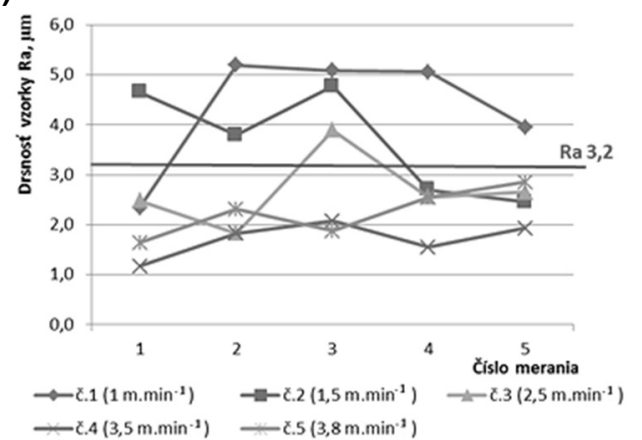

Fig. 8 Comparison of roughness at changing cutting speed;

(a) $11373, P=3650 \mathrm{~W}$, (b) 17240, $P=4000 \mathrm{~W}$

Figure 8 (a) shows the value of the mean arithmetic deviation of the section Ra of the sample 11373 cutting edge in micrometers with the required edge roughness value which cannot be exceeded. Based on the required roughness it is possible to compare if the cut samples comply with the roughness value Ra. From Figure 8 (a) we can say that the sample No. 1 does not meet the required roughness $\mathrm{Ra}$ of $1.6 \mu \mathrm{m}$. The roughness of other samples is satisfactory. From Figure 8 (b) we see that the worst changes of roughness in material 17240 are in samples No. 1, No 2 and No 3 which exceed the required roughness value Ra of $3.2 \mu \mathrm{m}$.

The best results have the samples No. 4 and No. 5, which do not exceed the defined roughness value $\mathrm{Ra}$ of $3.2 \mu \mathrm{m}$.

\section{DISCUSSION}

Important indicators of the laser cutting quality were the values of dimensional accuracy and roughness of cutting edges of the samples from materials 11373 and 17240. At changing of the cutting speed parameters it is necessary to compare the obtained measurement results. From the obtained results we can conclude that by means of laser cutting it is possible to influence the resulting dimensions of the defined samples and their roughness values by changing the cutting speed and laser output. By an appropriate change of the laser device parameters it would be possible to make a large scale production of serial components more efficient. In order to increase the efficiency of the cutting process, it is advantageous to increase the cutting speed or reduce the performance of the laser to the extent that it is possible to cut the parts with desired properties. 
In order to increase the efficiency of the cutting process of dimensionally identical samples, it is advisable to increase the cutting speed or reduce the laser beam power to such an extent that it is possible to cut samples with the desired properties.

\section{CONCLUSION}

According to that we have used the possibility to make the cutting process more efficient in a production organization and cut samples that are processed according to the defined requirements, we can determine the appropriate change of cutting parameters on the MSF laser device by means of the software.

The graphical comparison of the measured values published in this paper shows that it is possible to influence the resulting dimensions of the defined samples and their roughness values by changing the cutting speed and laser output. Due to the fact that we consider increasing of cutting speed to be more effective than reducing the laser beam performance, we propose the following cutting speed changes:

In order to preserve the required dimensional accuracy and roughness value of the cutting edge of the steel sample 11373, we suggest to increase the cutting speed from a preset parameter of $2.8 \mathrm{~m}$. $\mathrm{min}^{-1}$ to $3.25 \mathrm{~m}$. $\mathrm{min}^{-1}$ at the $3650 \mathrm{~W}$ laser output.

In order to preserve the required dimensional accuracy and the roughness value of the cutting edge of the stainless steel sample 17240, we suggest to increase the cutting speed from a preset parameter of $2.5 \mathrm{~m} \cdot \mathrm{min}^{-1}$ to $3.8 \mathrm{~m} \cdot \mathrm{min}^{-1}$ at the $4000 \mathrm{~W}$ laser output.

Suggested changes in cutting parameters for cutting defined samples could be beneficial in increasing the efficiency of the cutting process.

\section{REFERENCES}

Balla, J., Brozman, D., Mikuš, R. 2006. Wear investigation of tool cutting edge penetrating into soil by optical measurement and computer modelling. In The Iraqi journal of agricultural sciences, 2006, vol. 37 , no. 1 , p. $63-68$.

Benko, B. et al. 2000. Laser technology. Bratislava: STU Bratislava. 122 s. ISBN 80-277-1425-9.

Bernát, R. 2008. Influence of the shape and geometry of the cutting tool on the quality of the machined surface: dissertation work. Nitra: SPU. $266 \mathrm{s.}$

Gajtanska, M. et al. 2004. Lasers and their use in industry. Elected: Technical University of Zvolen. 295 s. ISBN 80-228-1398-2.

Geleta, V. 2013. Progressive machining technology. Bratislava: Slovak University of Technology. $163 \mathrm{s.}$ ISBN 978-80-227-3997-9.

Jiménez, A., Boto, F., Irigoien, I., Sierra, B., Suarez, A. 2017. Stability analysis of radial turning process for superalloys. In: Management Systems in Production Engineering 2017, Volume 25, Issue 3, Poland. ISSN 2450-5781, pp. 158-162.

Kováč I., Žarnovský J., Žitňanský J. 2005 Wear-resistant layers In: New trends in technology system operation: proceedings of the seventh conference with international participation, Prešov, 20.-21. October 2005. Košice: Technical University, 2005. ISBN 80-8073-382-1. with. 160-161.

Mičietová, A. 2001. Unconventional machining methods. Žilina: Publisher of the University of Žilina. 376 s. ISBN 80-7100-853-2.

Leonardo Technology. 2016. Fiber Principle - FIBER LASER [online]. @ 2016 [cit. 2018-02-05]. Available on: http://www.It.cz/e-learning/laser/princip-vlaknoveho-fiber-laseru.

Simon, V., Johansson, C.A., Galar D. 2017. Aggregation of electric current consumption features to extract maintenance KPIs. In: Management Systems in Production Engineering 2017, Volume 25, Issue 3, Poland. ISSN 2450-5781, pp. 183-190. 